\title{
浅析市政园林工程管理中的彩叶植物应用
}

杨泉松 ${ }^{1}$ 廖云东 $^{1}$ 徐扬帆 ${ }^{2}$

1 桐庐宇成市政园林建设有限公司 2 桐庐县建筑业管理处

DOI: 10.18686/bd.v1i9.855

[摘 要] 市政园林工程管理中的彩叶植物应用具有重要作用, 与草本花卉相比, 彩叶植物在绿化中栽培简单, 管理方便, 一次栽培可以多年观赏。同时由于色彩丰富, 适合不同季节的景观布置, 可以丰富构图, 调整色彩, 形成约丽的图案和不同 的季节效果。基于此,本文阐述了彩叶植物的主要类别,对市政园林工程管理中的彩叶植物应用进行了探讨分析。

[关键词] 彩叶植物; 类别; 市政园林工程管理; 应用; 原则

市政园林工程管理中的彩叶植物应用，丰富了南方城 市的色彩层次, 打破了北方城市的单调。此外彩叶树种大多 生长较慢, 可以形成数十年的景观效果, 并且彩叶灌木、地 被植物合适的运用,可以形成和好的景观层次。

\section{1 彩叶植物的主要类别}

彩叶植物依据彩叶植物不同特性, 其分类标准也不尽 相同。(1)依照季节划分, 彩叶植物可以细分为春色、常色以 及秋色叶植物。春、秋色叶植物是指在其生长期的某个阶段 中, 叶子呈现出彩色状态; 而常色叶植物则是指在其生长周 期全过程中, 其叶片均呈现出彩色状态。(2)根据植物的生 长习性划分, 可分为落叶型与非落叶型彩叶植物, 前者代表 有红枫、红叶李、红叶碧桃等; 后者代表有金心黄杨和金边 黄杨等。(3)按照彩叶出现的时间划分, 主要分为季节性和 非季节性彩叶植物, 前者指在某一个季节中植物出现彩叶 叶片, 代表植物有三角枫、五角枫、元宝枫以及变叶木等; 后 者指植物生长周期全过程中均有彩色叶片, 代表植物有红 叶碧桃、红枫、金心黄杨、紫叶李等。(4)按照色素划分, 彩叶 植物通常可分为: 红色叶植物 (枫香、红瑞木、拧筋械等), 黄 色叶植物 (复叶槭、银杏、杨树), 紫色叶植物 (紫叶李、紫叶 矮樱、紫叶桃), 蓝色叶植物, 镶边叶植物, 橙色叶植物等。

2 市政园林工程管理中彩叶植物应用的主要原则

市政园林工程管理中彩叶植物应用的原则主要有: (1) 均衡原则。将色彩各异的植物种类按均衡的原则配植, 景观 就显得稳定、顺眼。如色彩浓重的植物种类给人以沉重的感 觉; 相反, 色彩素淡的植物种类, 则给人以轻盈的感觉。根据 周围环境, 在配植彩叶植物时有规则式均衡(对称式)和自然 式均衡(不对称式)。规则式均衡常用于规则式建筑及庄严的 陵园或雄伟的皇家园林中。自然式均衡常用于花园、公园、 植物园、风景区等较自然的环境中。(2)统一性原则。其也称 变化与统一或多样与统一的原则。彩叶植物在应用设计时, 树形、色彩、线条、质地及比例都要有一定的差异和变化, 显 示出多样性, 但又要使它们之间保持一定相似性, 引起统一 感, 这样既生动活泼, 又和谐统一。变化太多, 过于繁杂的色 彩会失去美感、引起心烦意乱, 无所适从; 但平铺直叙, 没有
变化, 又会单调呆板。因此应用彩叶植物的配置造景要在统 一中求变化, 在变化中求统一。(3)功能和观赏性相结合原 则。园林绿化对彩叶植物的应用必须把植物的功能和观赏 价值集合在一起考虑。如果作为行道树, 应选择干性强、病 虫害少的植物; 若作为园景树, 应该选择树形和叶形均具较 高观赏价值的植物; 若作为垂直绿化, 应选择攀缘能力较强 的植物种类; 若用来点缀和做花坛, 可选择低矮的灌木; 若 作为地被, 则应用低矮的灌木或藤本植物; 若进行大面积造 景, 可选择的植物则较多。(4)科学性原则。科学性原则要 求应用彩叶植物的造景必须考虑植物能够健康生长, 符合 彩叶植物的生物学特性, 并能随彩叶植物的生长而使景观 发展变化。如紫叶小檗等要求全光照才能体现其色彩美,一 旦处于半阴或全阴的环境中, 叶片恢复绿色, 就失去了彩叶 效果。(5)调和的原则。调和的原则也称协调和对比的原则。 植物景观时要注意相互联系与配合, 体现调和的原则, 才能 使人享受到柔和、平静、舒适和愉悦的美感。找出近似性和 一致性, 配置在一起才能产生协调感。相反地, 用差异和变 化可产生对比的效果, 具有强烈的刺激感, 形成兴奋、热烈 和奔放的感受。因此, 在植物景观中常用对比的手法来突出 主题或引人注目。(6)文化、环境相融合原则。彩叶植物的配 置时应该挖掘其自身的文化价值, 通过植物的搭配使当地 文化与环境充分融合在一起。如杭州白堤上“柳暗花明”的 设计, 就表达出了“山重水复疑无路, 柳暗花明又一村”富于 哲理, 耐人寻味的经典名句。给景观赋予了文化韵味。合欢 的“圊家欢乐”、银杏的“公孙楖”的长寿等都是在设计时可 以发挥的文化素材。

\section{3 市政园林工程管理中的彩叶植物应用分析}

3.1 市政园林工程管理中彩叶植物与建筑配合的应用 分析。市政园林工程管理中的应充分考虑建筑的形状、体 量、质地、色彩等,使其与彩叶植物互相协调、均衡。首先如 体量大的建筑应该用体量大的彩叶乔木, 或者是用虽然单 株体量小, 但成丛成片的彩叶灌木, 以求达到均衡的效果。 其次建筑的色彩更是应该着重考虑的因素, 如果不考虑色 彩之间的搭配协调原则, 可能不但不能创造优美的景观, 反 
而会适得其反,甚至于破坏整个园林绿化。如在一些黑色的 建筑墙前配植红色叶植物如红枫, 不但显不出红枫的艳丽, 反而感到又暗又脏,形成一个败笔, 但如果配植一些开白花 的植物或鲜绝醒目的黄色叶植物。第三要充分考虑建筑的 质地, 对于质地粗䊅的建筑墙面应用较为粗壮的彩叶植物 来美化, 但于质地细淢的瓷砖、马赛克及较精细的耐火砖 墙, 则应选择纤细的彩叶植物来美化。也就是说, 我们要根 据不同的建筑物因地制宜配植不同种类的彩叶植物。

3.2 市政园林工程管理中彩叶植物与园林小品配合的 应用分析。园林小品是构成园林绿化的重要元素之一, 因此 正确处理彩叶植物与园林小品之间的关系，同样关系到整 个园林绿化的成败。不同的园林小品有不同的主题、涵义和 作用,所以我们应根据其不同的涵义和作用,配植不同色彩 的彩叶植物, 表现出不同的意境,构成具有一定特色的园林 绿化。而不是胡乱搭配, 任意配植。到时不但不能创造优美 的景观，反而可能会破坏园林小品所应表达的主题、涵义和 作用。如在绿地中白色的教师雕塑周围配以紫叶李、红叶 桃, 在色彩上红白相映, 则桃李满天下的主题会极为突出。 而假如在其周围任意地配植一些其它的园林植物, 则不能 烘托教师这个中心, 主题当然也不会这么突出, 植物配植也 就没有达到应有的、最好的效果。

3.3 市政园林工程管理中彩叶植物与水景配合的应用 分析。淡绿透明的水色是调和各种园林景物色彩的底色,金 色彩叶植物与绿水相配明快清心，红色彩叶植物与绿水配 植热烈激情, 紫色彩叶植物与绿水配植雅致神秘。在水池边 栽种彩叶小灌木倒映水中五彩斑澜。选择色彩以黄、蓝、红 为主, 彩叶植物如:美丽鸡爪槭、红花槭、石楠、紫叶山毛榉、 花叶扶桑、红桑等。平直的水面配植植物要等距离种植及整 形或修剪, 以免失去画意,栽植片林时, 留出透景线。同时水 边彩叶植物选择应注意选择有一定的耐水湿植物。

3.4 市政园林工程管理的彩叶植物在园林绿化中应用 分析。主要表现为:(1)孤植。其主要是通过植物的色彩和数 量对比来体现植物个体美与群体美。将彩叶植物孤植在景 观中心, 利用其艳丽的色彩引导游客的视线。孤植一般出现
在草坪内,运用树冠高大、树形丰满的彩叶植物较为适宜。 而对于庭院、花池等小景观来说, 应以株型紧凑的彩叶植物 为主。(2)丛植。丛植要重视景观的层次结构、色彩搭配、高 低错落。如以绿色的乔木作背景, 彩叶植物作前景或将亮色 调的彩叶植物丛植于浅色的建筑物前, 以丰富园林景观、活 跃园林气氛。如将紫色或黄色系列的彩叶植物加拿大紫荆、 苏格兰金莲花从植于浅色系的建筑物前，或以绿色的针叶 树种为背景，将花叶系列、金叶系列的种类与绿色树种丛 植, 均能起到锦上添花的作用。(3)群植。彩叶植物群植时的 密度要合理,不同品种不能混杂在一起,颜色要一致,使整 体色彩能充分展现出来。如紫叶山毛榉、紫叶矮樱、紫叶加 拿大紫荆、紫叶榛、紫叶梓树均可成片种植成风景林,其美 化的效果要远远好于单纯的绿色风景林。在国外的行道树 中, 以欧洲红花七叶树或高大的美国红枫单排或双排种植, 色彩缤纷,气势雄伟。在园林实践中,由于秋色叶观赏期较 长, 深受世界各地人民喜爱, 故广泛应用于园林之中, 将彩 叶植物成片栽植,营造出较有气势的景观。

\section{4 结束语}

随着低碳环保概念的深人，促进了市政园林工程建设 的发展, 同时明确了市政园林要以植物为主体,使得彩叶植 物以其丰富色彩在园林绿化建设中发挥着越来越重要的作 用，因此加强对市政园林工程管理中的彩叶植物应用进行 分析具有重要意义。

\section{参考文献：}

[1]张红梅.彩叶植物的分类及其在园林绿化中的应用 [J].装饰装修天地,2015

[2] 田二强. 彩叶植物在园林景观配置中的应用研究 [J].山西农经, 2016

[3]范沝.论彩叶植物在园林景观设计中的应用 [J]. 科 学与财富,2016

[4]刘志永.彩叶植物在园林景观配置中的作用及应用 前景[J].现代园艺,2016

[5]王天婧.彩叶植物在园林绿化中的适应性应用 [J]. 中国绿色画报,2017 